\title{
THE HAWKMOTH MACROGLOSSUM GYRANS AND ITS INTERACTION WITH SOME PLANT SPECIES AT VISAKHAPATNAM
}

\author{
A.J. Solomon Raju, S. Purnachandra Rao, V. Ezradanam, Rashda Zafar, P. Roop Kalpana and P. Kiran Kumari
}

Department of Environmental Sciences, Andhra University, Visakhapatnam, Andhra Pradesh 530003, India

Email: ajsraju@yahoo.com

\begin{abstract}
The Hawkmoth, Macroglossum gyrans was studied with regard to its nectar host plants and floral characteristics such as flower shape, colour, nectar volume, sugar concentration and sugar types. Further, the foraging period and pollination role of $\mathrm{M}$. gyrans were also examined.
\end{abstract}

KEYWORDS

Floral characters, foraging schedules, Hawkmoth, Macroglossum gyrans, pollination

\begin{abstract}
Hawkmoths (Lepidoptera: Sphingidae) are one of the most peculiar creatures of nature. These creatures are generally characterized as large, strong flying lepidopterans (D’Abrera, 1986). Sphingidae is primarily a tropical family (Rothschild \& Jordan, 1903) and comprises of about 200 genera with 1,000 species distributed worldwide except in the colder regions (Arnett, 1985). The number of genera and species is greatest in tropical latitudes and decreases towards higher latitudes (Grant, 1983). Like all other lepidopterans, hawkmoths are holometabolous with egg, larval, pupal and adult stages, each stage is distinctly marked in the life cycle. The eggs are globular, or slightly flattened and smooth (Rothschild \& Jordan, 1903). Larvae are brightly coloured with a characteristic "sphingid horn" at one end. They are external leaf feeders and often eat specific food plants (Holland, 1903). Most of the larvae are serious pests and feed on many different crops such as tomatoes and tobacco (Borkent \& Greenway, 1997). Pupae are formed in leaf litter or underground, and rarely on the host plant. Adults are nectarivorous (Boggs, 1987). Nectar is usually rich in carbohydrates, amino acids, lipids, antioxidants, alkaloids, proteins, vitamins, etc. (Dafni, 1992).
\end{abstract}

The adult hawkmoths fly by day, by night, or in the crepuscular period (Opler, 1983). They are highly specialized flower visitors equipped with a long, thin and very flexible proboscis (Meeuse $\&$ Morris 1984). Some hawkmoths hover at flowers like hummingbirds and suck nectar. While doing so, they collect pollen on proboscis and head. Their proboscis is evolved in parallel with long, tubular corollas of flowers they visit. The eyes of hawkmoths contain three classes of photoreceptors sensitive in green, violet and ultraviolet region of the light spectrum (Schwemer \& Paulsen 1973; Bennett \& Brown 1985). The flower patterns reflecting UV wavelength (not visible to humans) might be significant to sphingid feeding behaviour. Hawkmoth flowers are typically white to human eye (White et al., 1994). Haber and Frankie (1989) reviewed the pollination role of hawkmoths in tropical flowers. They suggest that hawkmoths can be effective pollinators because they can carry large pollen loads on specific body parts such as the proboscis, cover long distances rapidly, favouring pollination of rare plants, and move readily between plants. Hawkmoths are long- lived, mate repeatedly, lay few eggs per host plant, and oviposit through adult life, a reproductive pattern that requires both sexes to cruise large habitat patches seeking mates, host plants, and frequent refueling stations. This behaviour favours outcrossing of widely spaced plants as well as common, mass flowering trees.

Hawkmoth pollination has been reported to be more common in tropical habitats than elsewhere (Grant, 1983; Opler, 1983). Hawkmoth species are quite abundant in neotropical forests and pollinate $5-10 \%$ of the trees and shrubs (Janzen, 1983; Bawa et al., 1985; Haber \& Frankie, 1989). There appears to be no studies on hawkmoth-flower associations, particularly with reference to floral syndromes and pollination in paleotropics.

In this paper, we report some aspects of interactions between the hummingbird hawkmoth, Macroglossum gyrans Walker and the flowers of different plant species. This study will throw light on the importance of $M$. gyrans in the pollination of some plant species and the dependence of the hawkmoth on these plants for nutrition during adult life.

\section{Materials And Methods}

Field studies were carried out at Visakhapatnam $\left(17^{\circ} 42^{\prime} \mathrm{N} \&\right.$ $\left.82^{0} 18^{\prime} \mathrm{E}\right)$ on Macroglossum gyrans with regard to its flowervisiting activity, foraging schedules and behaviour, and floral reward collected. Based on the published information regarding the floral colours utilized by the hawkmoths, the plant species that produce white or cream flowers were selected and observed for the foraging activity of $M$. gyrans. Further, the plant species which produce other floral colours were also observed for the visits of M. gyrans. After noting the hawkmoth visits on these selected species, observations were made from the early morning $(0400 \mathrm{hr})$ to the late evening $(2100 \mathrm{hr})$ to record the exact timing of foraging activity of the hawkmoth on each plant species. Occasional observations were also made on some plant species for the foraging activity of the hawkmoth during night time.

The foraging behaviour was observed in terms of the mode of approach, landing, the type of forage it collects, and contact with essential organs. The flowers were examined for their 
Table 1. Floral details and foraging period of the Hawkmoth Macroglossum gyrans

\begin{tabular}{|c|c|c|c|c|c|c|c|c|}
\hline Plant species & Habit & Anthesis time & Corolla shape & Flower colour & $\begin{array}{l}\text { Volume } \\
(\mu \mathrm{I})\end{array}$ & $\begin{array}{l}\text { Nectar chara } \\
\text { Sugar conc } \\
(\%)\end{array}$ & $\begin{array}{l}\text { Dominant } \\
\text { sugar }\end{array}$ & $\begin{array}{l}\text { Hawkmoth 's } \\
\text { Foraging period }\end{array}$ \\
\hline \multicolumn{9}{|l|}{ Alangiaceae } \\
\hline Alangium lamarkii & Tree & 24 hours & Non-tubular & Greenish-white & 23 & $21-35$ & Gsf & $\begin{array}{l}0600-0900 \\
1700-1900\end{array}$ \\
\hline \multicolumn{9}{|l|}{ Bignoniaceae } \\
\hline$\overline{\text { Tecoma stans }}$ & Tree & $\begin{array}{l}0500-0600 \\
1500-1600\end{array}$ & Tubular & Yellow & 3 & $35-42$ & Gsf & $\begin{array}{l}0600-0900 \\
1600-1900\end{array}$ \\
\hline \multicolumn{9}{|l|}{ Caesalpiniaceae } \\
\hline Tamarindus indica & Tree & $2300-0400$ & Non-tubular & Dusty white & 5 & $6-8$ & Gsf & $0500-1000$ \\
\hline \multicolumn{9}{|l|}{ Lamiaceae } \\
\hline Hyptis suaveolens & Shrub & $0700-1700$ & Tubular & Blue & 3 & $6-8$ & Gsf & $\begin{array}{l}0730-0900 \\
1700-1800\end{array}$ \\
\hline \multicolumn{9}{|l|}{ Moringaceae } \\
\hline Moringa oleifera & Tree & $0500-0900$ & Non-tubular & White & 11 & $19-26$ & Gsf & $0600-1000$ \\
\hline \multicolumn{9}{|l|}{ Oleaceae } \\
\hline Jasminum angustifolium & Shrub & $1730-1830$ & Tubular & White & 2 & $25-30$ & Sgf & $\begin{array}{l}1800-1900 \\
0600-1000\end{array}$ \\
\hline \multicolumn{9}{|l|}{ Rubiaceae } \\
\hline Morinda tinctoria & Tree & $1700-1900$ & Tubular & White & 2 & $11-14$ & Gsf & $1730-1930$ \\
\hline Xeromphis spinosa & Shrub & $\begin{array}{l}0400-0900 \\
1700-2100\end{array}$ & Tubular & Milky white & 80 & $18-27$ & Gsf & $\begin{array}{l}0500-1000 \\
1730-2000\end{array}$ \\
\hline \multicolumn{9}{|l|}{ Sapindaceae } \\
\hline Sapindus emarginatus & Tree & $0700-0800$ & Non-tubular & Light cream & 8 & $22-48$ & Sgf & 0530-0900 \\
\hline \multicolumn{9}{|l|}{ Verbenaceae } \\
\hline Stachytarpheta jamaicensis & Shrub & 0400-0500 & Tubular & Violet & 4 & $7-12$ & Gsf & $0530-1000$ \\
\hline Tectona grandis & Tree & $0300-0400$ & Non-tubular & White & 1 & $18-28$ & Gsf & $0430-0900$ \\
\hline
\end{tabular}

anthesis time, shape, colour, nectar volume, sugar concentration and sugar types. After making preliminary observations on the timing of anthesis, the exact anthesis period was determined. Floral shape and colour was noted. The nectar volume was measured by squeezing the nectar into a graduated micropipette. Nectar sugar concentration was determined by using a hand refractomer. For the analysis of sugar types of nectar, paper chromatography method was used (Harborne, 1973). Nectar was placed on Whatman No. 1 filter paper along with standard samples of glucose, fructose and sucrose. The paper was run descendingly for 35 hours with a solvent system of butanol: acetone: water $(4: 5: 1)$, dried at $105^{\circ} \mathrm{C}$ in an oven for five minutes and sprayed with aniline-hydrogen-phthalate. The nectar spots developed were then compared with the spots of the standard sugars and recorded the types of sugars in the nectar. The probing behaviour of the hawkmoth was carefully observed with the naked eye and also with binoculars as when required. Ten specimens of the hawkmoth, two each from the flowers of five plant species were collected, proboscides removed, placed in aniline-blue on the glass slide and observed under microscope for pollen grains in order to evaluate the role of the hawkmoth in pollination. Observations were also made on the foraging speed and inter-plant movements of the hawkmoth.

\section{Observations}

Eleven plant species selected for the study belong to nine different families. They are provided along with their habit, flowering period, the floral aspects such as colour, shape, anthesis time, nectar volume, sugar concentration and sugar types, and the foraging period of the hawkmoth in Table 1. The tubular flowers are produced by Tecoma stans, Hyptis suaveolens, Jasminum angustifolium, Morinda tomentosa, Xeromphis spinosa and Stachytarpheta jamaicensis while nontubular, open type flowers are produced by the remaining plant species. Yellow flowers are produced by $T$. stans, blue flowers by $H$. suaveolens, violet flowers by $S$. jamaicensis and white or cream flowers by the remaining plant species. Anthesis occurs around the clock in A. salviifolium, day-long in $H$. suaveolens, early morning and afternoon in T. stans, early morning and late evening in $X$. spinosa, late night to early morning in $T$. indica, evening in $J$. angustifolium and $M$. tomentosa and morning in the remaining plant species. Nectar volume per flower is 1$80 \mathrm{ml}$. Nectar sugar concentration is $6-48 \%$ and the sugar types are sucrose, glucose and fructose. Sucrose is the dominant sugar in J. angustifolium and S. emarginatus while it is glucose in all other species. Of the plant species in the study, $A$. salviifolium and $J$. angustifolium are uncommon while the rest are common in the study region. The flowers of A. salviifolium, T. indica and J. angustifolium are light scented while those of the remaining plants are odourless.

Macroglossum gyrans oviposited on the tender leaves of Morinda tinctoria and used the same host plant for nectar collection during adult life. It used all other plant species as nectar host plants only. The hawkmoth was found to visit the flowers during early morning and evening hours only despite the availability of flowers throughout the day and night. It began foraging activity soon after the occurrence of anthesis, continued for 1-4 hours and disappeared at the flowers.

The hawkmoth probed the flowers for nectar only. While probing, it hovered at the flowers, stretched out its long, flexible 
proboscis and inserted into the tubular or non-tubular corolla to take nectar. It spent 2-3 seconds at each flower and visited a number of flowers in quick succession in a very short time. It made very frequent visits to different conspecific plants in quest of nectar. On each plant species, the hawkmoth while probing for nectar made contact with the sex organs effecting pollen transfer from its proboscis to the stigma of the flower. Ten specimens of the hawkmoth visiting the tubular (T. stans, J. angustifolium and $M$. tinctoria) and non-tubular (A. salviifolium and $T$. grandis) flowers were captured and their proboscides were observed under the microscope for pollen grains. The proboscides of all ten specimens were found with pollen grains ranging from 40 to 790 and this was considered that the hawkmoth acted as a pollinator. Of the plant species observed in the study, $X$. spinosa was exclusively foraged by the hawkmoth, while all other plant species also by different insect species.

\section{Discussion}

Hawkmoth flowers have been reported to have tubular corollas (Baker, 1961; Gregory, 1964; Faegri \& van der Pijl, 1979; Grant, 1983). A deep corolla tube has been considered to be an adaptation to protect the flower against nectar robbers which do not pollinate the flowers and to allow only pollinators to harvest the nectar (Barrows, 1976). The flowers that cater to hawkmoths open in the evening and display their overwhelming fragrance at that time. They are snow-white or light coloured, offer no landing platform and may have fringed petals, possibly for guidance. Many have both visual and olfactory nectar guides. The corolla tube is long and narrow, something which discriminates against other, short-tongued visitors, and there is an abundance of nectar (Meeuse \& Morris, 1984). In the present study, the flowers visited by $M$. gyrans show anthesis at different times of the day and night but mostly during early morning and evening time. Light fragrance comes from only three plant species, A. salviifolium, T. indica and $J$. angustifolium and the other plant species do not emit any fragrance. Nectar guide is absent in all species except $H$. suaveolens. The flowers include both tubular and non-tubular ones. The former category does not offer landing platform while the latter category does. Haber and Frankie (1982) reported that in the Costa Rican dry forest, a few dry season hawkmoth flowers lacked tubular corollas. The non-tubular flowers in the present study are available during dry season and also at other times. M. gyrans utilized them through out the year. The floral colours of the plant species visited by $M$. gyrans are mostly white or cream. Other floral colours are yellow, blue and violet. Proctor and Yeo (1972) reported that primarily hawkmothpollinated flowers tend to have pale coloured or white flowers as an adaptation to the crepuscular or nocturnal habits of their visitors. They also noted from Knoll (1925) that when hawkmoths were trained on blue and violet flowers, they preferred intermediate and darker shades to paler ones. In line with these reports, $M$. gyrans in the present study appears to have the ability to utilize the floral colours other than white or cream. But, the yellow, blue and violet flowers in the present study are primarily adapted to bee-visitation (Victor, 1999). All this suggests that $M$. gyrans does not discriminate the flowers of different species only on the basis of floral colour, shape and fragrance.

Hawkmoths are exclusively nectarivorous, strong and rapid fliers and their flowers contain more nectar, hidden in long, narrow corolla tubes (Opler, 1983). The nectar volumes and concentrations of hawkmoth flowers have been reported by different workers. The nectar volume is $130.6 \mathrm{ml} /$ flower (Opler, 1983), 42.6ml/flower (Cruden et al., 1983) and 23.4-61.02ml/ flower (Eisikowitch et al., 1986). The nectar concentration is $8.18 \%$ (Percival, 1965), 21.3\% (Cruden et al., 1983), 22.1\% (Pyke \& Waser, 1981), 24\% (Baker \& Baker, 1983a,b) and 26.2-36.1\% (Eisikowitch et al., 1986). In the present study, the nectar volume ranged from $1-80 \mathrm{ml} /$ flower and nectar concentration $6-48 \%$. It indicates that $M$. gyrans avails both high and very low volume of nectar with low to moderate sugar concentration. The flowers that produce low volume of nectar are arranged in clusters or aggregated and this type of arrangement compensates the low volume of nectar and enables the hawkmoth to derive more energy in a single trip to the flowers (Cruden et al., 1976). Hawkmoths, in general, take nectars with low sugar concentration of about $24 \%$. Because, low viscosity is necessary to allow the quick uptake of nectar by the hawkmoths which only spend a very brief period at the flowers and also the nectar must flow into a narrow tube when being removed from the flowers (Baker, 1975; 1978). In the present study also, the nectar sugar concentration in all the plant species is in the same range. In $S$. emarginatus flowers, the nectar sugar concentration is low at anthesis and gradually the concentration increases towards evening. But, the hawkmoth forages only during morning hours when the sugar concentration is low. In all plant species of the present study, the floral nectar is composed of glucose, sucrose and fructose. Sucrose is dominant in J. angustifolium and S. emarginatus and glucose in the remaining plant species. This study is in strong contrast with the generalization made by Baker and Baker (1983a,b) that the flowers visited by hawkmoths are predominantly sucroserich.

Cruden et al. (1976) reported that the foraging activity of the hawkmoths depends on the ambient temperature. They observed a decrease in the foraging activity of the hawkmoths when ambient temperature is below $15^{\circ} \mathrm{C}$ and this is probably a consequence of the failure of hawkmoths to warm up. Hawkmoths also do not forage when temperature is high, especially during late morning to early afternoon. This suggests that hawkmoth activity either declines or stops at high and low temperatures. On the other hand, Baker (1975) stated that temperature may effect the rate of nectar extraction. Because, the rate of nectar extraction is a function of the nectar's viscosity which increases exponentially with decrease in temperature. Similarly, the increase in temperature may lead to the evaporation of water content in the nectar thereby increasing its sugar concentration. The high viscosity nectars are not suitable for extraction by hawkmoths. Therefore, hawkmoths visit the flowers mostly during morning and evening hours or immediately after anthesis because the nectar during this period is low in viscosity and also the ambient temperature is low. 
These two factors are quite favourable for hawkmoths to extract floral nectars. The foraging schedules of M. gyrans in the present study conform to this generalization.

Hawkmoths form a distinct guild of pollinators in both tropical and temperate ecosystems (Baker, 1961; Gregory, 1964; Cruden et al., 1976; Grant \& Grant, 1983; Bawa et al., 1985; Nilsson et al., 1987; Haber \& Frankie, 1989). They are efficient in the extraction of floral nectars and in so doing effect pollination. In the present study, all the plant species breed through geitonogamy and xenogamy which, in essence, require pollen vectors. T. stans and $H$. suaveolens in addition, breed through autogamy (Das, 1996; Victor, 1999; Rao, unpublished data). M. gyrans is the exclusive pollinator of $X$. spinosa. The latter has not been visited by any other insect species although different species of bees, wasps, flies, beetles and butterflies are available in the study area. M. gyrans oviposits on the tender leaves of $M$. tinctoria which occurs in the study region and the availability of $M$. gyrans and hence, pollination in X. spinosa is assured. In other plant species, M. gyrans is one of the pollinators, but it remains to be an effective pollinator because of its efficiency in extracting nectar with great speed and sure contact of its proboscis with the sex organs of flowers. $M$. gyrans plays an important role in the pollination of plant species. Therefore, the larval and nectar host plant species of $M$. gyrans must be protected in order to perpetuate and increase the population size of the hawkmoth and exploit the pollination services rendered by it. Further, intensive studies must be carried out to unfold the exhaustive list of nectar host plants of M. gyrans and its extended role in plant-pollination.

\section{REFERENCES}

Arnett, R.H. Jr. (1985). American Insects: A Handbook of the Insects of America North of Mexico. Van Nostrand Reinhold Company, New York.

Baker, H.G. (1961). The adaptations of flowering plants to nocturnal and crepuscular pollinators. Quarterly Review of Biology 36(1): 64-73. Baker, H.G. (1975). Sugar concentrations in nectars from hummingbird flowers. Biotropica 7(1): 37-41.

Baker, H.G. (1978). Chemical aspects of pollination of woody plants in tropics, pp. 57-82. In: Tomlinson, P.B. and M.H. Zimmermann (Eds.) Tropical Trees as Living System. Cambridge University Press, Cambridge. Baker, H.G. and I. Baker (1983a). A brief historical review of the chemistry of floral nectar, pp. 81-152. In: Bentley, B. and T. Elias (Eds.). The Biology of Nectaries. Columbia University Press New York. Baker, H.G. and I. Baker (1983b). Floral nectar sugar constituents in relation to pollinator type, pp. 117-141. In: Jones, C.E. and R.J. Little (Eds.). Handbook of Experimental Pollination Biology, Scientific and Academic Editions, New York.

Barrows, E.M. (1976). Nectar robbing and pollination of Lantana camara (Verbenaceae). Biotropica 8(2): 132-135.

Bawa, K.S., S.H. Bullock, D.R. Perry, R.E. Coville and M.H. Grayum (1985). Reproductive biology of tropical low land rain forest trees II. Pollination Systems. American Journal of Botany 72(3): 346-356. Bennet, R.R. and P.K. Brown (1985). Properties of the visual pigments of the moth Manduca sexta and the effects of detergents, digitonin and Chaps, Vision Research 25(12): 1771-1781.

Boggs, C.L. (1987). Ecology of nectar and pollen feeding in Lepidoptera, pp. 369-391. In: Slansky, F. Jr. and Rodriguez (Eds.). John Wiley and Sons, New York, Nutritional Ecology of Insects, Mites and Spiders.

Borkent, C. and L. Greenway (1997). Natural History: Sphinx Moths (Family Sphingidae) in British Columbia. Biological Notes and Field Key based on specimens in the collection at the Royal British Columbia
Museum, Electronic Document.

Cruden, R.W., S. Hermann and S. Peterson (1983). Patterns of nectar production and plant-pollinator co-evolution, pp. 80-125. In: Bentley, B. and T. Elias (Eds.). The Biology of Nectaries. Columbia University Press, New York.

D' Abrera, B. (1986). Spingidae Mundi. Hawkmoths of the World. E.W. Classey Ltd. Faringdon Oxon., 226pp.

Dafni, A. (1992). Pollination Ecology: A Practical Approach. Oxford University Press, Oxford, 250pp.

Das, R.K. (1996). Sexual systems and pollination in some tropical wild plant species. Ph.D. Thesis. Andhra University, Visakhapatnam, India (Unpublished).

Eisikowitch, D., Y. Ivri and A. Dafni (1986). Reward partitioning in Capparis spp. along ecological gradient. Oecologia (Berlin) 71(1): 41-50.

Faegri, K. and L. van der Pijl. (1979). The Principles of Pollination Ecology. Pergamon Press, Oxford, 244pp.

Grant, V. (1983). The systematic and geographical distribution of hawkmoth flowers in the temperate North American flora. Botanical Gazzette 144(3): 439-449.

Grant, V. and K.A. Grant (1983). Behaviour of hawkmoths on flowers of Datura meteloides. Botanical Gazzette 144(2): 280-284.

Gregory, D.P. (1964). Hawkmoth pollination in the genus Oenothera. Aliso 5(4): 357-419.

Haber, W.A. and G.W. Frankie (1982). Pollination of Luebea (Tiliaceae) in Costa Rican Deciduous forest. Ecology 63: 1740-1750.

Haber, W.A. and G.W. Frankie (1989). A tropical hawkmoth community: Costa Rican dry forest sphingidae. Biotropica 21: 155-172.

Harborne, J.B. (1973). Phytochemical Methods. Chapman and Hall, London, 260pp.

Holland, W.J. (1903). The Moth Book: A Popular Guide to a Knowledge of the Moths of North America. Doubleday, Page and Company, New York, 345pp.

Janzen, D.H. (1983). Costa Rican Natural History. University of Chicago Press, Chicago, 965pp.

Knoll, F. (1925). Lichtsinn und Blutenbesuch des Falters Von Deilephila livornica: Z. Vergl. Physiol 2(3): 320-380.

Meeuse, B. and S. Morris (1984). The Sex Life of Flowers. Facts on File, New York, 148pp.

Nilsson, L.A., L. Jonsson, L. Ralison and E. Randrianjohany (1987). Angraecoid orchids and hawkmoths in Central Madagascar: Specialized pollination systems and generalist foragers. Biotropica 19(4): 310-318.

Opler, P.A. (1983). Nectar production in a tropical ecosystem, pp. 3079. In: Bentley, B. and T. Elias (Eds.). The Biology of Nectaries. Columbia University Press, New York.

Percival, M.S. (1965). Floral Biology. Pergamon Press, London, 172pp. Proctor, M. and P. Yeo (1972). The Pollination of Flowers. Taplinger Publishing Company, New York, 378pp.

Pyke, G.H. and N.M. Waser (1981). On the production of dilute nectars by hummingbirds and honeyeater flowers. Biotropica 13(2): 260-270.

Rothschild, L.W. and K. Jordan (1903). A Revision of the Lepidopterous family Sphingidae. Novitates Zoologicae (9) Supplement 1-972.

Schwemer, J. and R. Paulsen (1973). Three visual pigments in Deilephila elpenor (Lepidoptera: Sphingidae). Journal of Comparative Physiology 86(3): 215-229.

Victor, P. (1999). The Floral Ecology of Some Tropical Plant Species. Ph.D. Thesis. Andhra University, Visakhapatnam, India (Unpublished). White, R.H., R.D. Stevenson, R.R. Bennett, D.E. Cutler and W.A. Haber (1994). Wave length discrimination and the role of ultraviolet vision in the feeding behaviour of hawkmoths. Biotropica 26(4): 427-435.

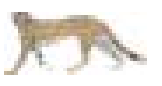

